\title{
A descriptive reference framework for the personalisation of e-business applications
}

\author{
Panayiotis Koutsabasis • Modestos Stavrakis • \\ Nikos Viorres · Jenny S. Darzentas • \\ Thomas Spyrou • John Darzentas
}

Published online: 14 August 2008

(C) Springer Science+Business Media, LLC 2008

\begin{abstract}
Personalisation is widely considered as a critical element of contemporary electronic businesses. However, despite the wealth of scientific work on personalisation, the definition of the term remains blurred with as consequence a lack of clarity as to what to design or evaluate when it comes to this area of an e-business. E-business stakeholders, including designers, managers and customers, need to understand the significance of personalisation features for many reasons including: guidance for design and evaluation, user appeal and implications for e-business functionality. The paper introduces a descriptive framework for personalisation aspects of e-businesses, in business-to-consumer (B2C) situations, that is related to typical e-business functionality. The proposed framework classifies previous research and extends it to provide e-commerce stakeholders with a vocabulary for analysing e-businesses, for comparing personalisation features, and for explaining e-business commerce evaluation results. The framework is applied to the evaluation of the personalisation features of contemporary clothing e-businesses, and conclusions are drawn for the readiness of this sector to adopt personalisation requirements.
\end{abstract}

P. Koutsabasis $(\varangle) \cdot$ M. Stavrakis · N. Viorres · J.S. Darzentas · T. Spyrou · J. Darzentas Department of Product and Systems Design Engineering, University of the Aegean Hermoupolis, Syros, 84100 Greece

e-mail: kgp@aegean.gr

M. Stavrakis

e-mail:mod@aegean.gr

N. Viorres

e-mail: nviorres@aegean.gr

J.S. Darzentas

e-mail: jennyd@aegean.gr

T. Spyrou

e-mail: tsp@aegean.gr

J. Darzentas

e-mail: idarz@aegean.gr 
Keywords Personalisation · E-business · Framework · Case study $\cdot$ Clothing e-business

\section{Introduction}

Personalisation is widely considered as a critical element of contemporary e-businesses/electronic commerce applications. Personalisation does not apply only for the electronic world; nevertheless technology offers the possibility to remember innumerable customers and adapt services and products to their needs and characteristics. The Personalisation Consortium (http://www.personalization.org) defines the aims of personalisation as to 'better serve the customer by anticipating needs; make the interaction efficient and satisfying for both parties; and build a relationship that encourages the customer to return for subsequent purchases'. On the Web, personalisation usually refers to adapting Web content, presentation, and interaction so that these satisfy user characteristics and preferences. This being said, it is widely acknowledged that personalisation for the Web is not simply an area with technical dimensions but 'an enterprise strategy designed to address tailoring customer interactions across sales, marketing and customer service' [24].

Functions of Web applications that are classified as personalisation are wideranging, from simple display of the end-user's name on a Web page, to product recommendations and user-driven (mass) customisation of products. Likewise, personalisation technologies range from the use of cookies and dynamic page generation, to information filtering, sophisticated user profiling and rule-based inference engines. Despite the wealth of scientific work on personalisation, the concept remains blurred with as consequence a lack of clarity as to what to design or evaluate when it comes to this aspect of conducting e-business. As a result, e-business stakeholders may not safely form an overview about the possibilities and impact of personalisation for e-business. Managers need to be in a position to assess the benefits of various personalisation features and methods in order to make investment decisions. Customers need to be aware of the implications of personalisation regarding their interaction strategies and privacy concerns. Designers need to identify guidelines for design and assessment of personalisation with respect to user characteristics and preferences.

The paper introduces a descriptive reference framework which sets out elements of knowledge that make up personalisation of e-businesses in relation to typical e-business functionality and can be used to inform design and evaluation practices of e-business stakeholders for B2C e-commerce. The framework organises previous research on personalisation and extends it to provide e-business stakeholders with a vocabulary for analysing e-businesses, for comparing personalisation features, and for explaining evaluation results. The framework is applied in the evaluation of the clothing e-business, and conclusions are drawn regarding both the applicability of the framework and the level of personalisation of this sector.

\section{Related work and scope}

The significance of personalisation for e-business has been emphasised in many contexts. Personalisation is considered as an important factor for adding value to 
e-business services [3] and thus achieving one-to-one marketing: 'the single most important way to provide value is to know the customers and serve them as individuals' [15]. A number of user behaviour studies also indicate that consumer loyalty is strengthened by personalised services; for example Telang and Mukhopadhyay [32] demonstrate that loyalty becomes much stronger when the users use personalised features. Furthermore, particular e-business functions such as providing current order and delivery status information to customers, accessing (explicit or implicit) profiling information and customer relationship management (CRM) mechanisms, like integrating purchase histories from all customer touch points, (including Web sites, and brick-and-mortar stores, [1]) are also considered important features of a personalised service.

Personalisation is related to other relevant areas of work such as user modelling, recommender systems and (mass) customisation. User modelling typically emphasises the construction of esoteric computer-based models, often on the basis of cognitive science, about user mental activities and behaviours in order to adapt system usability or as a basis for interactive help. Recommender systems [22] provide targeted recommendations to users on the basis of aggregated information that may come from other users and/or their own preferences thus achieving filtering of available information. Customisation occurs when the user can configure an interface and/or create a profile explicitly, when the control of the look and/or content is user-driven [5]; while mass customisation is typically related to tangible products (rather than services) and the availability of (demand-driven) production capabilities that actually allow customers to tailor products according to their preferences and characteristics. The mainstream understanding of personalisation is typically at a higher level of abstraction in comparison to these concepts, referring to the requirement of adapting content, presentation and interaction, rather than the means for its implementation.

The paper focuses on a specific application of personalisation, that of business to consumer (B2C) e-commerce. This form of e-business is often associated with the buying and selling of information, products, and services via the Internet, which seeks to replace or complement the traditional sales channel with online channel to consumers [11]. The paper adopts a wide perspective for the concept of personalisation that aims to be of use for design and evaluation work to e-business stakeholders, including e-business managers and decision makers, designers and developers of personalisation for e-businesses and the large user/customer base. To achieve this, it critically reviews existing research and practices and extends them by organising them in a way that is practically integrated typical e-business functionality.

Research on personalisation can be qualitatively identified into two major streams: personalisation research by itself and personalisation in specific applications. Core personalisation research includes, among others: user profiling [9, 34], data mining [30], information filtering [12], agent-based interaction [25], soft computing techniques [10], virtual communities [27] and Web accessibility [13]. This research needs to be applied to particular application areas including: education [19], digital TV [2], web browsing in general (mylook.com; my.yahoo.com), e-business (for example Amazon.com uses several diverse personalisation techniques to recommend books and gifts, and provide coupons to their customers), and others.

Related work on conceptual frameworks for personalisation across the aforementioned dimensions of research includes: 
- Schubert and Leimstoll [28] introduce a systematic personalisation framework for e-business that describes the basic steps required by e-business applications and visualises the personalisation cycle. This framework presents a specific model for personalisation based on explicit and implicit user profiles, narrowing down options for design and development and can serve as a guide to designers of personalisation.

- Sicilia [29] proposes a conceptual framework regarding personalisation in e-commerce that includes issues distinguishing them as either marketing-oriented and/or technical. The framework is useful for teaching purposes, but does offer itself for neither the promotion of awareness among e-business stakeholders nor the provision of guidance to designers.

- Murthi and Sarkar [17] present a framework for personalisation that allows for identification of key players in the personalisation process for e-business, as well as, the key stages of personalisation from a customer perspective, however, apart from aiding comprehension, the paper does not explain how this knowledge can be operationalised in practice.

- Riemer and Totz [23] introduce a comprehensive framework for personalisation and mass customisation that focuses on the economics and feasibility of switching from traditional ways of making e-business to personalised and mass customised. Their work is useful for assisting decision making of e-business managers but lacks guidance at the level of e-business design.

Another aspect of related work is that of the identification of personalisation features, or to be more exact clusters of features, that may be designed to offer an individualised interaction experience. Personalisation features have been described from various perspectives and for various application contexts (Table 1). The work of Kobsa et al. [15] provides a comprehensive account of personalisation features for

Table 1 Clusters or types of personalisation features

Authors $\quad$ Scope $\quad$ Personalisation features

$\begin{array}{lll}\begin{array}{l}\text { Alpert et al. } \\ \text { (2003) [1] }\end{array} & \text { E-commerce } & \text { Personal book, universal profile, subscription-based services, per- } \\ & \text { sonalized service and support, recommendations, adaptive presen- } \\ & \text { tation, personal preferences, adaptive navigation, live help or sales } \\ & \text { support, personalized feedback, accessible transaction history, loy- } \\ & \text { alty programs, future purchase considerations, your personal store, } \\ & \text { built by an expert }\end{array}$

Danculovic et al. Web Link personalization; Content personalization; Structure personal(2001) [7]

Kim (2003) [14] Web isation; Client-side personalisation

Lookup of personal records in a database/file; Lookup of a rule base or a profile database; Data mining; Weblog mining; Text mining; Online analytical processing (OLAP)

Kobsa et al. Web

(2001) [15] hypermedia

User input data; user data acquisition methods; user model representation and secondary inferences; hypermedia adaptation production

Wu et al. (2003) E-commerce Control personalisation; Content personalisation; Link personalisa[36] Web sites tion; Customized Screen Design personalisation; Anthropomorphic personalization. 
the purpose of providing design aid on the basis of review work; while other work typically defines personalisation features rather intuitively.

A number of issues that stem out of the current state of the art on personalisation and have been significant for the motivation of this paper, can be summarised in the following:

- There are various approaches, (technologies and open specifications) to personalisation, as well as some conceptual frameworks that are usually not offered to practitioners in ways that can be taken up easily.

- Much work in the area offers narrow perspectives of personalisation with the consequence that this work needs to be situated with conceptual frameworks, at least descriptively.

- The majority of related work is presented in a way that is isolated from typical e-business functionality and as a result interested parties neither are in the position to comprehend the potential of personalisation, nor can they assess personalisation solutions.

The proposed framework differs from previous work on e-business personalisation in the following ways:

- It integrates a variety of observations and practices of personalisation with e-commerce functionality.

- It addresses a particular type of application of personalisation, that of $\mathrm{B} 2 \mathrm{C}$ e-commerce.

- It is intended to support understanding, design and evaluation of e-businesses by all the B2C stakeholders including users (customers), designers and managers (owners).

- It demonstrates its applicability through an evaluation case study that of the clothing e-business.

\section{Viewing personalisation in relation to typical e-business functions}

To be usable, a reference framework for personalisation features for e-businesses needs to be accessible to all e-business stakeholders and incorporate meaningfully those aspects of related work that might constitute features important for e-business purposes. The proposed descriptive framework incorporates personalisation requirements from a customer perspective avoiding references to technical issues. In order to create an operational personalisation framework that can be of use to e-business stakeholders it is critical that features of personalisation are identified and classified in a practical way.

The work described in this paper approaches this task by organising personalisation features in relation to typical e-business functionality. Typical e-business functionality according to Blackwell et al. [4] includes the major stages of search for information, pre-evaluation of alternatives, purchase decision and post purchase behaviour. Our approach (outlined in Table 2) operationalises these stages by posing the following questions that are related to e-business personalisation functionality: 
Table 2 Outline of the descriptive framework for personalisation of e-business

\begin{tabular}{|c|c|c|c|}
\hline & $\begin{array}{l}\text { Framework } \\
\text { element }\end{array}$ & Basic questions & $\begin{array}{l}\text { Typical personalisation } \\
\text { features/clusters }\end{array}$ \\
\hline 1 & User information & $\begin{array}{l}\text { What customer information is required for } \\
\text { personalization of e-business services? }\end{array}$ & $\begin{array}{l}\text { Customer characteristics } \\
\text { Customer preferences } \\
\text { Identification information }\end{array}$ \\
\hline 2 & $\begin{array}{l}\text { Knowledge and } \\
\text { awareness } \\
\text { infrastructure }\end{array}$ & $\begin{array}{l}\text { How do customers become aware about } \\
\text { interesting products? } \\
\text { How customers obtain knowledge about } \\
\text { products and services? } \\
\text { How can customers communicate with } \\
\text { other customers? }\end{array}$ & $\begin{array}{l}\text { E-mail } \\
\text { Automatic notifications } \\
\text { Multi-linguality } \\
\text { Virtual communities } \\
\text { News-events } \\
\text { Product reviews }\end{array}$ \\
\hline 3 & $\begin{array}{l}\text { Support for customer } \\
\text { search }\end{array}$ & $\begin{array}{l}\text { How can an e-business guide customer } \\
\text { search to interesting products with } \\
\text { minimum time and maximum relevance? }\end{array}$ & $\begin{array}{l}\text { Keywords } \\
\text { Advanced search } \\
\text { Product catalogue } \\
\text { Personal guide } \\
\text { Product proposals }\end{array}$ \\
\hline 4 & $\begin{array}{l}\text { Support for customer } \\
\text { selection }\end{array}$ & $\begin{array}{l}\text { How is the customer supported for making } \\
\text { purchase decisions? }\end{array}$ & $\begin{array}{l}\text { Personal collection } \\
\text { Virtual try } \\
\text { Designer's opinion } \\
\text { Comprehensive information } \\
\text { Product comparison } \\
\text { Discount offers } \\
\text { Order tracking }\end{array}$ \\
\hline 5 & $\begin{array}{l}\text { Support for mass } \\
\text { customisation }\end{array}$ & $\begin{array}{l}\text { To which degree may products be } \\
\text { customised? } \\
\text { How is the customer supported during the } \\
\text { customization task, minimizing/avoiding } \\
\text { errors? }\end{array}$ & $\begin{array}{l}\text { Aesthetic customization } \\
\text { Dimension and fit customisation } \\
\text { Customisation help } \\
\text { Visualisation of customisation }\end{array}$ \\
\hline
\end{tabular}

- 'What' type of questions, which are related to required information and knowledge:

- customer information (data) for personalisation

- knowledge infrastructure that supports personalisation-personalization features should not remain simply at the level of providing information to customers but help them transform this information to useful knowledge for action in an e-commerce environment.

- 'How' type of questions, which are related to the fundamental customer functions:

- search for information, products and services

- purchase decision-selection of information, products and services

- (mass) customisation of products and services.

3.1 What customer information is required for an e-business to provide personalised services?

An e-business can record (implicitly), ask for (explicitly), store and statistically process customer information in order to personalise content, presentation and interaction. Unless information about customers is made available to the e-business 
information system, personalisation would be, in most cases, impossible. The work of Kobsa et al. [15] helpfully lists user input data for e-business personalisation as comprising of:

- User data: demographic data, user knowledge, user skills and capabilities, user interests and preferences, user goals and plans

- Usage data: observable usage (selective actions, temporal viewing behaviour, ratings, purchases and purchase-related actions, other confirmatory and disconfirmatory actions) and usage regularities

- Environment data: software environment, hardware environment, locale.

Although this enumeration of types of customer information is useful for detailed design purposes, it may not be directly operational for evaluation purposes since it includes some aspects that are not visible to the user such as those produced from usage or assumptions regarding cognitive user properties. Therefore, the framework described here organises customer information in the following (more abstract) clusters:

- Customer characteristics: they are related to physical customer information. This type of information may be required for various purposes including creating accessible e-business services (for example tailoring e-business services for sight impaired people) or identifying products that correspond to customer requirements in terms of size and fit, or ergonomics and available space (e.g. clothes, furniture, etc.).

- Customer preferences: the term denotes customer information about (categories of) products such as buying history, preferences and ratings. This information is often collected by e-businesses in terms of a user profile or usage that may be explicitly provided by the customer or gradually built by the system during interaction.

- Customer identification information: this includes "hard data" such as name and contact information.

3.2 What knowledge and awareness infrastructures are offered by e-businesses to customers?

Personalisation of e-business services requires that customers are aware of issues of interest through their interaction with the e-business or other customers. Knowledge and awareness infrastructures need to be established by e-businesses in order to enhance customer trust and provide means for communicating customer requirements. The following aspects of knowledge and awareness infrastructure are identified:

- Electronic mail: the most usual means of communication between customers and an e-business.

- Automatic notifications: e-businesses often provide customers with notifications that may be of interest (e.g. about news, products, saved queries, etc.). The frequency and relevance of notifications need to be assessed by customers; otherwise they often are annoying for them [16]. There is a fine line between usefulness and disruption. 
- Multi-linguality: the adaptation of the e-business content and services (e.g. currency) to the customer's preferred language is a highly desirable personalisation feature.

- Virtual community: a virtual community establishes a communication channel among customers that enables them to express concerns and answer questions without the direct intervention of the e-business. Virtual communities can enhance customer trust [21] by establishing a means for frequent communication, exchange of opinions and assistance.

- News-events: this type of awareness infrastructure helps customers to see up-todate information about e-business activities, but it also provides the sense that 'someone is there' which enhances the feeling of trust for customers.

- Product reviews: are provided by customers to report on the quality of e-business products and services. Product reviews implement the 'word of mouth' in the electronic world and provide an alternative source of recommendation information, in which one can find product information, product experience and product popularity from a user's perspective [35].

\subsection{How is personalisation supported during customer search?}

Searching is a critical e-business function. Very often simply including keywords and advanced search functions, are not usually effective due to the plethora of search results. Search that is designed following other, more personalised forms helps to minimise "noise". Personalisation features that are related to customer searching include:

- Keyword-based search

- Advanced keyword-based search

- Product catalogue-visualisation of products, which can be related to link personalization [7]

- Personal guides/assistants-it is a common feature of brick-and-mortar stores and the metaphor has been implemented in various ways in e-business, including personal software assistants/agents [37] and live help [1]

- Customised product proposals_-about interesting items are important features of contemporary e-businesses, which are often implemented through automated mechanisms that produce recommendations (recommender systems).

\subsection{How is personalisation supported during customer decision?}

Customer purchase decision (selection of appropriate products and services) is the next group of e-business functionality (pre-evaluation according to [4]). Personalised support for user decisions happens in physical business by various means including try-out programs and facilities, comparison with other products and discount offers.

- Personal collection/taxonomy-the possibility of collecting interesting products (e.g. wish list) that may be reviewed at a later stage or at another time, allowing time to think or comparisons to other e-businesses.

- Virtual try-this is related to product-based e-businesses such as the clothing and furniture sector. 
- The opinions of the creator/designer-customers often value the possibility to include explanations about the rationale of product or service design by the creators themselves. The designer view also contributes to a more humane interface of the e-business.

- Comprehensive product or service information-which critically supports customer decisions and is a pre-requisite for any personalisation feature.

- Product comparison-for example in terms of price, style, content, and others. Product comparison enables users to perform online a typical shopping activity of real-life.

- Discount offers-personalized discount offers to customers are possible in various ways including combinations of product offerings, gifts, discounts to loyal or major customers, and others.

- Order tracking - customer decision is also supported by ensuring that post order personalised service are part of e-business functionality, including order tracking which been valued as a personalised feature in related work as well [1].

\subsection{How is the mass customisation of products and services supported?}

Electronic services can be offered in terms of various schemes and products can be offered in various forms including styles and sizes. Although personalisation is not usually related to mass customisation, it seems that the end-user customisation of products and services is an ultimate form of personalisation, which can be interlinked to demand-driven production and requires integration to supply chain management [20]. Related e-business features include:

- Customisations of product aesthetics - customers require customisation of tangible products according to their aesthetic preferences including style, colour, and design features.

- Customisation of size, dimensions and fit-tangible products like clothes and furniture need to be customized according to customer requirements like body size and physical space/ergonomics considerations respectively.

- Customisation help-when customers can customize aspects of products and services they need to have available help about the possibilities and constraints of customisations.

- Visualisation of customisation-unless customers can see the result of their customisations, they may not be certain about the actual result.

The value of the framework is that it provides in a descriptive, non-technical manner important clusters of personalisation features that can be operationalised by ebusiness stakeholders such as managers (owners), designers and customers during design and evaluation tasks (for example it may be incorporated in e-business design and evaluation methods and practices). The framework addresses the open issues identified in the previous section by synthesising related work relative to typical e-business functionality, thus directly constraining the focus of this work to B2C ebusiness. However, the proposed framework should not be seen as a complete account of personalisation but as a basis for refinement in the aforementioned dimensions. The work acknowledges that personalisation needs to be applied and evaluated in context. As noted by Alpert et al. [1], 'personalization features popular in one e-commerce environment may not be effective or useful for other e-Commerce domains.' 


\section{Case study: Personalisation of contemporary clothing e-businesses}

The framework presented here can be applied in combination with various design and evaluation methods and techniques ranging from heuristic methods and expertbased evaluations to contextual methods involving users in the design and evaluation process. To support this claim, a heuristic evaluation of a specific type of e-business has been conducted in order to allow for a general view of the status of personalised services provided by these e-businesses. The goal of the evaluation was to qualitatively assess the level of personalisation of contemporary clothing e-businesses by identifying personalisation aspects not addressed sufficiently and opportunities for further development.

\subsection{Clothing e-businesses selected}

Examples from a specific sector were selected in order to investigate personalisation features in context. In particular the clothing business was selected mainly because the marketed products can support a variety of personalisation features. In addition, in this sector there is a large customer base waiting to see their requirements addressed, before they engage in the extensive use of this way of purchasing garments. The clothing market (both in Europe and the US) faces many threats, both internal and external, which can be primarily addressed by technological innovation and provision of added-value services. Thus it follows that personalisation should definitively be one aspect of this development.

The number of clothing e-businesses has grown rapidly over the last few years; however the level of electronic services is below average in comparison to other sectors, at least for Europe [8]. This is mainly attributed to the fact that the vast majority of clothing businesses are small and medium enterprises (SMEs). Clothing e-businesses mainly use the following e-business models:

- Business presentation/self-advertisement-this includes a simple business presence on the Internet providing contact information and perhaps a product catalogue.

- Electronic retailers (shops) — these include online shopping and order functionality

- Clothing/fashion portals (vertical portals) — these integrate links to particular e-businesses and various other functions including news and advertisements

- Business to business (B2B) infrastructures, e.g. clothing exchanges-these infrastructures promote $\mathrm{B} 2 \mathrm{~B}$ e-commerce mainly by organising exhibitions and transactions of products and manufacturing equipment.

The study examined a large number of e-businesses in the area of clothing, from which twenty-two (22) were selected to be assessed across the elements of the proposed framework. The two basic criteria for selection were that the selected e-businesses should be e-retailers in order to focus on e-businesses following one business model that best fits the $\mathrm{B} 2 \mathrm{C}$ perspective of the proposed framework, and that these should offer a rich set of functionality to customers including to some extent personalisation options. The selected e-businesses are briefly presented in Table 3, while their basic e-business functionality is shown in Fig. 1. All selected e-businesses 


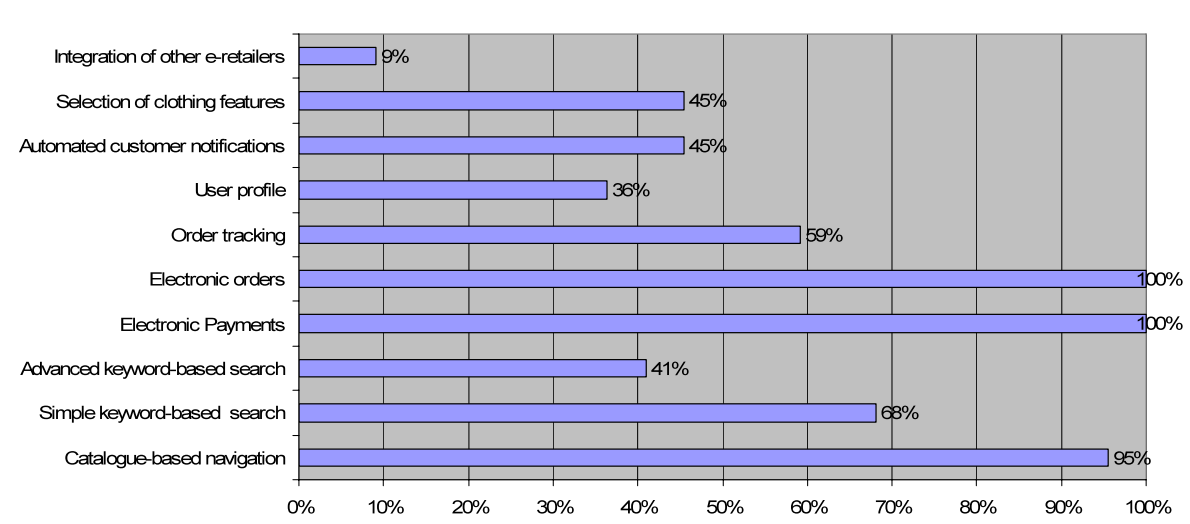

Fig. 1 Basic functionality of the selected clothing e-businesses

Table 3 Clothing e-businesses selected for the study

\begin{tabular}{lll}
\hline & URL & Brief description \\
\hline 1 & http://al-farah.com & Islamic clothing for women \\
2 & http://www.beyondfleece.com & Outwear \\
3 & http://www.bivolino.com & Custom-made shirts \\
4 & http://www.bluefly.com & Clothing (general) \\
5 & http://www.footballfanatics.com & Sport team clothing \\
6 & http://www.gap.com & Clothing (general) \\
7 & http://www.jcrew.com & Clothing (general) \\
8 & http://www.landsend.com & Clothing (general) \\
9 & http://www.llbean.com & Clothing (general) \\
10 & http://www.nike.com & Sport equipment \\
11 & http://www.micamisa.com & Custom-made shirts \\
12 & http://www.promod.com & Women clothing \\
13 & http://www.red21boys.com & Boy's clothing \\
14 & http://www.shakatime.com & Hawaiian clothing \\
15 & http://www.shirtsbyshik.com & Clothing (general) \\
16 & http://www.shopchic.net & Women clothing \\
17 & http://www.spclothing.com & T-shirts \\
18 & http://www.textilestation.com & T-shirts \\
19 & http://www.t-shirts.com & T-shirts \\
20 & http://www.workwearhouse.co.uk & Work wear \\
21 & http://www1.bloomingdales.com & Clothing (general) \\
22 & http://www1.macys.com & Clothing (general) \\
\hline & & \\
\hline
\end{tabular}

provide electronic payment and ordering functions, while other important e-business functions are also present in large percentages such as catalogue-based browsing and order tracking. 


\subsection{Applying the personalisation framework to the clothing e-business}

The first stage of the evaluation was conducted independently by the authors of the paper, in order to allow for a personal, unbiased application of the framework. Each participant went through the e-business sites a number of times in order to identify their personalisation elements. Participants completed simple forms about the elements of personalisation functionality along with personal comments about findings identified during interaction with the e-business environments. For most cases participants required 20-30 minutes to go through each e-business site.

After the individual evaluations, all participants had an interpretation session during which they compared their results and discussed the different understandings that appeared during the application of the framework. The interpretation session identified different understandings about some elements of the framework and resolved these discrepancies for a unified set of evaluation results, which are presented later in this section.

\subsubsection{Customer information}

Customer information (Fig. 2) is prerequisite for achieving personalisation in e-business; the e-businesses that do not utilise extensively customer information simply cannot provide advanced personalised services. All studied e-businesses were e-retailers, so they all asked for customer identification information for ordering and payment functions.

A large number of the studied e-businesses (72.7\%) make use of user preferences in various ways. In most cases, customers have a wide range of choices for selecting colour and style of clothing products; in a few cases this can be achieved in terms of specific parts of clothing as well, such as the inclusion of inside pockets in a jacket, the colour of sleeves, the style of a collar, including embroidery, and others. This information is typically provided by users during interaction and not in terms of user profiles or other non-contextual activities.

Body measurements are required by clothing e-businesses, when they are offering mass customisation functions regarding the correct fit of clothes and especially

Fig. 2 Personalisation in the clothing e-business: customer information

\section{Customer information}

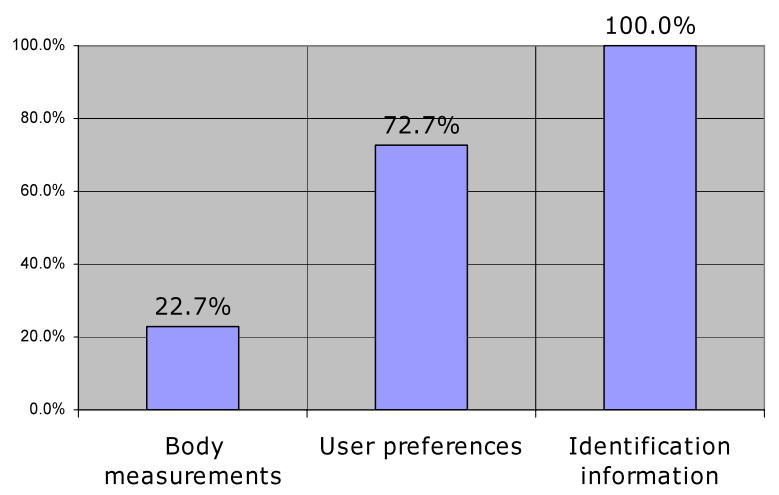




\section{Knowledge and awareness infrastructure}

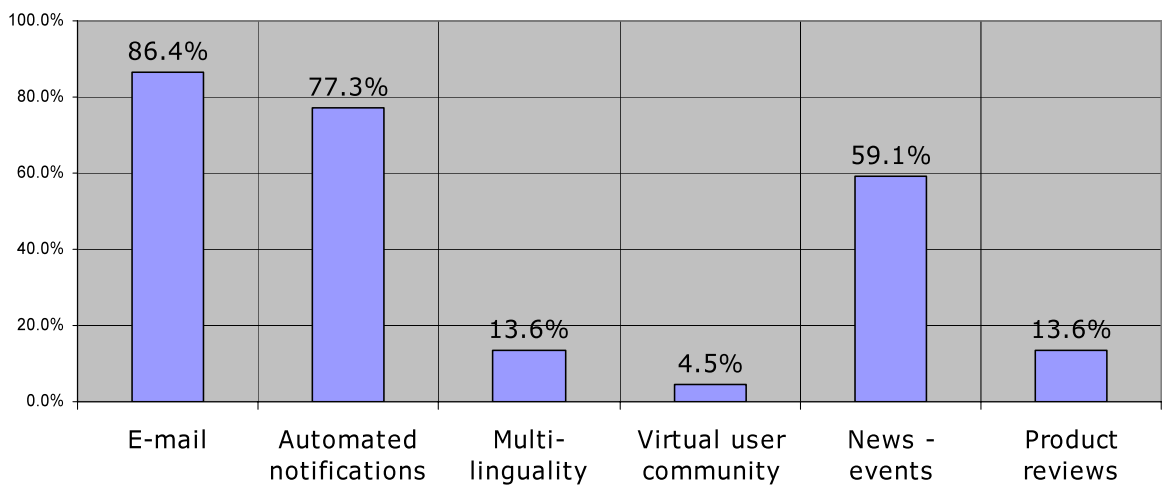

Fig. 3 Personalisation in the clothing e-business: knowledge and awareness information

no standard size charts. Only five of the selected e-businesses $(22.7 \%)$ offer this advanced set of possibilities to their customers. Body measurements are provided either by asking customers to provide specific measurements relative to their body or in terms of specific clothing (e.g. shirts—-sleeve length, circumference of waist, and others).

\subsubsection{Knowledge and awareness infrastructure}

The knowledge and awareness infrastructures in the clothing sector (Fig. 3) are characterised by the extensive use of e-mail $(86.4 \%)$ for B2C communication in terms of providing help and customer support as well as for automated notifications $(77.3 \%)$ about potentially interesting information. In addition most of the studied clothing e-businesses $(59.1 \%)$ include a section with news and events on their site.

Besides the aforementioned infrastructure the studied clothing e-businesses make limited use of other knowledge and awareness services. Only three e-businesses (13.6\%) adapt content and services to another language than English. Surprisingly, only one e-business (4.5\%) supported a virtual user (customer) community by providing a blog where customers can report on their experiences interacting with the e-business. Similarly, only three e-businesses (13.6\%) provide means for customer reviews of products and services, with the consequence that there is a limited opportunity for customers to express their opinion about marketed products on the site. These results are in stark contrast to other e-business sectors such as music and books, where the use of virtual communities and product reviews is extensive.

\subsubsection{Support for customer search}

The primary means for searching for products of interest in clothing e-businesses is the catalogue-based search $(95.5 \%)$, which provides visual presentation of clothes and their basic features (Fig. 4). One might speculate that this is a habit from mail order shopping that was catalogue based. A well-designed catalogue for clothes is 
Support for customer search

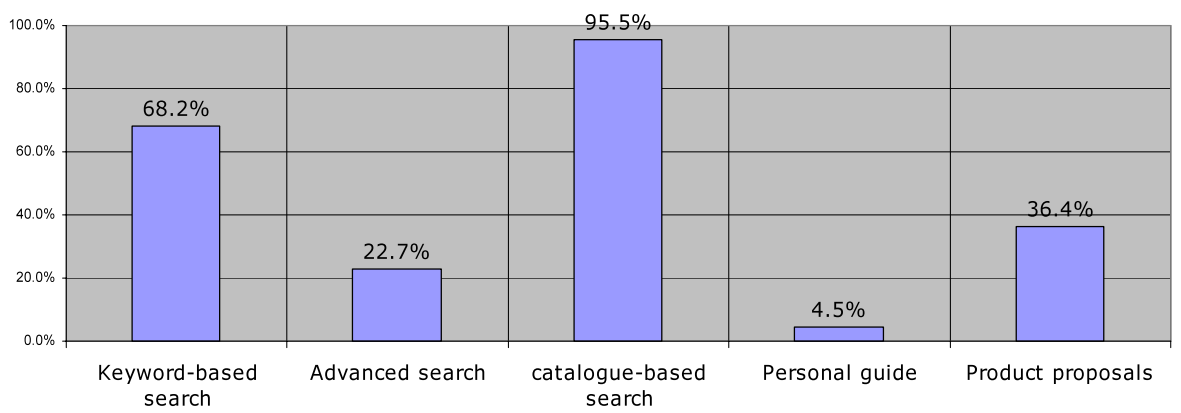

Fig. 4 Personalisation in the clothing e-business: support for customer search

indeed a very usable way to explore a collection - that is not always the case however since some catalogues were not accessibly designed. For example, there was no text alternative to describe goods for users unable to access graphics (blind users, users with low bandwidth). Keyword-based search is also prominent in the two thirds of the studied e-businesses (68.2\%), while advanced search is a limited function (22.7\%).

Product proposals (purchase suggestions) amount to a considerable number (36.4\%) of the e-businesses examined. These mainly refer to "go-together" items that match in terms of style an item that the customer has just selected. Other types of product suggestions also include best-sellers. Finally, a last element of personalised support to customer search is that of a personal guide, which is supported by one e-business $(4.5 \%)$ as a live help function (implemented via chat) to customers online. Other types of personal guides such as software agents have not been identified in the clothing sector.

\subsubsection{Support for customer decision}

Customer decision is a critical step in the online purchase process. The distinguishing element in this respect of the clothing e-businesses studied (Fig. 5) is that of the comprehensive product presentation $(86.4 \%)$, which included pictorial and textual description, stock, size and colour availability, and other such elements. Certainly some product presentations were more comprehensive than others containing different perspective views of clothing, models wearing the clothes, and estimated shipping dates.

Attractive discount offers are an important element of e-business and the majority of the studied clothing e-businesses have included this feature to their functionality to a large extent $(63.6 \%)$. Some e-businesses offer discounts in a fully personalised way-e.g. in batch orders, in combination to another purchase or in terms of customer credits, but the majority of e-businesses offer discounts in comparison to their brickand-mortar stores. Order tracking, which refers to the ability of customers to see the stage of their order after the online purchase, also appears in an important percentage of the e-businesses examined $(59.1 \%)$.

The designer's view was available to half of the studied clothing e-businesses $(50 \%)$, helping customers understand the important design features of clothes in a 
Support for customer decision

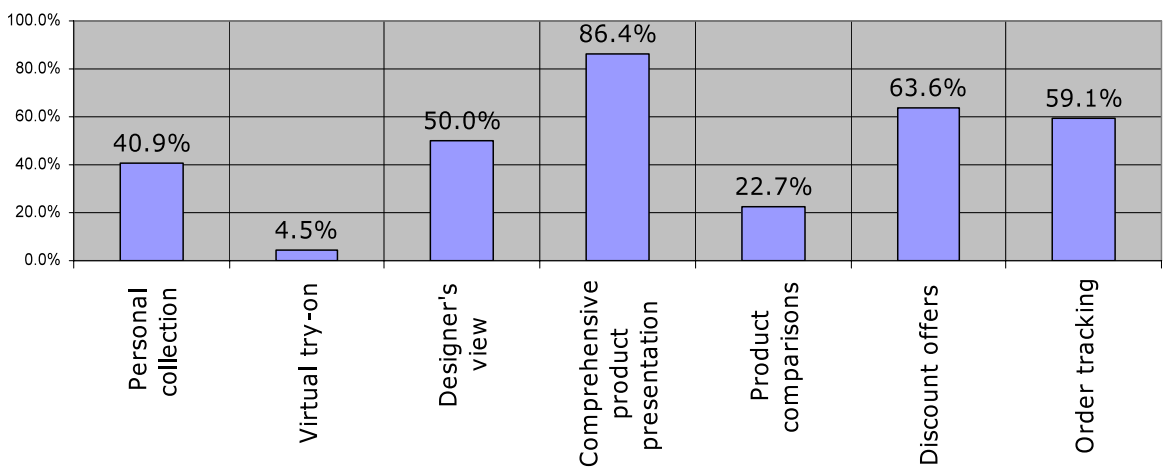

Fig. 5 Personalisation in the clothing e-business: support for customer decision

far more comprehensive way than simply by looking at a static picture or model. The designer's view can enhance customers' knowledge about a specific product also be revealing the rationale behind a particular design which helps customers to identify whether their personal needs/requirements can be met by the specific product.

Another personalised feature seen in a considerable percentage of the clothing e-businesses studied is the personal collection (40.9\%) (i.e. in most cases in the form of a wish list) that customers can build during interaction and store at the e-business site for future reference. Wish lists can be also used to track customer preferences.

An important customer activity that contributed to making purchase decisions is related to making product comparisons. Product comparisons can occur in terms of price, style, order availability and other characteristics that may be unique for each customer. Unfortunately, product comparisons are still not extensively implemented $(22.7 \%)$ in the clothing e-business sector.

A typical feature that critically affects the customer purchase decision in the clothing business is the trying-on of clothes; this is typical practice at brick-and-mortar stores, however it is a difficult feature to implement at an e-business environment. Only one of clothing e-business $(4.5 \%)$ has a sophisticated implementation of virtual try-on and a virtual model that can be designed to resemble the customer body metrics.

\subsubsection{Support for mass customisation}

Mass customisation (Fig. 6) is considered the ultimate form of personalisation as far as tangible products are concerned. Mass customisation regarding aesthetics refers to the customer potential to select or configure product elements that are related to style, colour, and clothing feature availability (such as pockets, zippers, buttons, etc.). Half of the clothing e-businesses examined (50\%) incorporate aesthetic customisation functions, which differ in variety and extent of features supported. For example there are e-businesses that support the customisation of clothes in terms of adding custom clothing parts, such as internal pockets or embroidery, and others that simply offer a wide range of options (about colours, sizes, styles) for the user to select from. 
Support for mass customisation

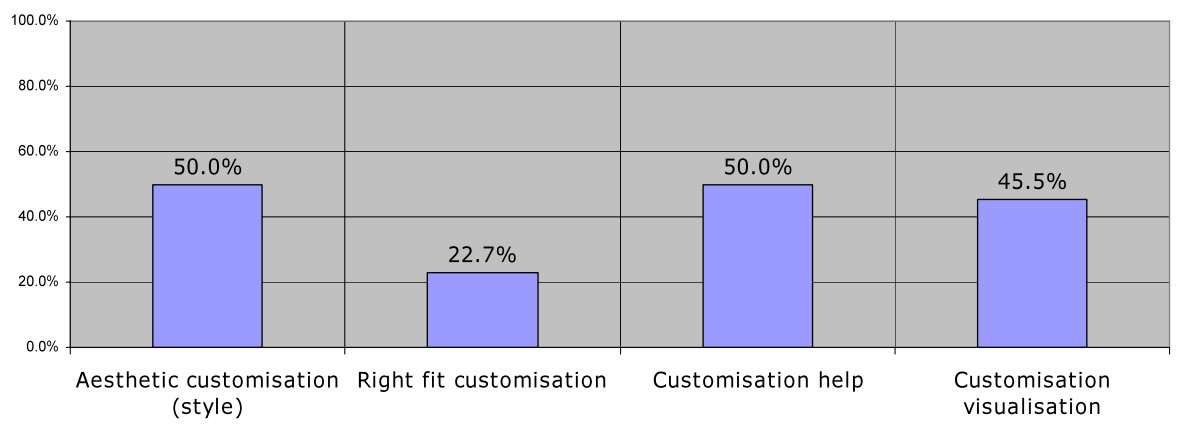

Fig. 6 Personalisation in the clothing e-business: support for mass customisation

Customisation for correct fit is a challenge for clothing e-business. This function does away with size charts for clothes, which are not satisfactory for body dimensions that diverge from average and differ among producer businesses in the sector. Mass customisation for correct fit requires from customers to provide body or clothing measurements and from e-businesses to manage their production in an individualised, demand-driven way. Five of the selected e-businesses $(22.7 \%)$ have responded to this challenge by incorporating the function of mass customisation for correct fit, which was provided as a step-by-step process for customers.

The support for mass customisation is an important personalisation aspect of the clothing e-business. Although customisation help and visualisation were present for almost all cases of e-businesses, it was felt (by the participants of the evaluation study) that the usability of mass customisation for correct fit should be substantially improved for some e-businesses, in order to allow for easier exploitation of this function from customers. In addition the small uptake of such advanced personalisation features shows that there is much potential for clothing e-businesses regarding the exploration of mass customisation features of clothing.

\subsection{Applicability of the framework: discussion}

The descriptive framework for personalisation of e-business was used as a basis to conduct a heuristic evaluation of contemporary clothing e-businesses. Heuristic evaluations are widely used in usability research [18] because they provide a fast, costeffective way to qualitatively assess the conformance of a user interface to a given set of rules or guidelines (heuristics) with the use of experts. On the other hand, heuristic evaluations cannot provide contextual results since that they do not include end-users and pragmatic usage situations. A critical aspect of heuristic evaluations is that experts first perform their evaluation alone and then jointly interpret the results of their individual study. The identification and discussion about different results is the most important element of this method.

For the evaluation of personalisation of contemporary clothing e-businesses, the participants did not have identical results after the end of their evaluations. The personalisation features that created different results among evaluation participants were: 
- Support for customer search-personal guide: although the notion of a personal guide is explained as an autonomous or interactive software assistant (agent) or live help (human assistant) one participant felt that an extensive customer service, even if not interactive or live, should also be included in the definition. As a result, the results of this participant scored highly than the others in this respect $(33.3 \%$ instead of the $4.8 \%$, which was finally agreed after discussion).

- Support for customer decision-designer's view: some e-businesses explicitly included the designer opinion about an item, while other present satisfactory design information but they do not associate this to specific designers. The participants agreed, after a discrepancy in their results to adopt a broader approach to the evaluation and accept that the latter e-businesses successfully addressed this feature.

- Support for mass customisation-aesthetic customisation: a considerable number of e-businesses provide customer options that affect the aesthetics of clothes including selecting colour, style and fabric. However the extent to which such personalisation features are offered differs significantly among e-businesses. The inconsistencies between the individual scores then led the participants to collaboratively re-examine once again the e-business sites in order to reach to an agreed suggestion per case.

Issues such as those identified above are common practice in heuristic evaluations. It should be clear that the aim of any such type of evaluation is not the mere scoring of elements, but their collaborative interpretation by participants on a basis that is provided by an empirical framework. Furthermore, if the personalisation framework is utilised in a contextual methodological approach (for example a user-based evaluation including pragmatic e-business scenarios), it would be probably required to refine some of the clusters of features in order to allow qualitative results in terms of other related personalisation issues such as ensuring user privacy [33], promoting trust [6], providing effective recommendations [31] and others. In any case, the important result of the exercise is that a cost-effective method has been produced that has provided valuable insight to the status of personalisation of contemporary clothing ebusinesses and has identified various areas of further development in dimensions such as the incorporation of user communities, customer-based product reviews and mass customisation for correct fit of clothing items.

\section{Conclusions}

The paper introduced a descriptive reference framework for personalisation aspects of e-businesses. The focus of this work was to review existing work on personalisation and extend it by integrating this to typical e-business functions. The paper adopts a wide perspective for the concept of personalisation that aims to be of use for design and evaluation work to e-business stakeholders, including e-business managers and decision makers, designers and developers of personalisation for e-businesses and the large user/customer base. The proposed framework differs from previous work on e-business personalisation by achieving an integration of various practices of personalisation with e-commerce functionality for $\mathrm{B} 2 \mathrm{C}$ e-commerce situations 
and by demonstrating its applicability through an evaluation case study of clothing e-retailers.

The applicability of the personalisation framework was demonstrated by its use for evaluation of contemporary e-businesses in the clothing sector. The application of the framework identified personalisation areas that have been inadequately exploited by the e-businesses examined, such as the use of online communities, customer-based product reviews and mass customisation for correct fit. It needs to be noted that the proposed framework should not be seen as a complete account of personalisation but as a basis for refinement in the identified dimensions, which may be re-emphasised or further extended depending on the context of application of this work.

Schonberg et al [26] recognize that, while there are several ways to personalise a Web site, it is not clear how and what to personalise to provide features that customers will value. The proposed framework provides guidance in this respect since it can be used as a sound basis for a range of practical applications including the aid for decision-making for e-business managers and customers, and its incorporation into design and evaluation methods for designers of e-commerce applications.

\section{References}

1. Alpert, S. R., Karat, J., Karat, C.-M., Brondie, C., \& Vergo, J. G. (2003). User attitudes regarding a user-adaptive e-commerce Web site. User Modeling and User-Adapted Interaction, 13, 373-396.

2. Ardissono, L., \& Maybury, M. (2004). Special issue on user modeling and personalization for television, preface. User Modeling and User-Adapted Interaction, 14, 1-3.

3. Awad, N., \& Krishnan, M. S. (2006). The personalization privacy paradox: An empirical evaluation of information transparency and the willingness to be profiled online for personalization. Management Information Systems Quarterly, 30(1), 13-28.

4. Blackwell, R. D., Miniard, P. W., \& Engel, J. F. (2001). Consumer behaviour (Vol. 9). Fort Worth: Dryden Press.

5. Bonett, M. (2001). Personalization of Web services: Opportunities and challenges. Ariadne, 28. http://www.ariadne.ac.uk/issue28/personalization/intro.html.

6. Briggs, P., Simpson, B., \& De Angeli, A. (2004). Personalisation and trust: a reciprocal relationship? In Designing personalized user experiences in e-commerce. Human-computer interaction series (pp. 39-55). Dordrecht: Kluwer Academic.

7. Danculovic, J., Rossi, G., Schwabe, D., \& Miaton, L. (2001). Patterns for personalized Web applications. In Sixth European conference on pattern languages of programs. http://hillside.net/europlop.

8. Electronic business in the textile, clothing and footwear industries: Adherence to traditional production and trading summary of sector studies, e-business W@tch, March 2005. http://www.ebusiness-watch.org.

9. Fan, W., Gordon, M. D., \& Pathak, P. (2005). Effective profiling of consumer information retrieval needs: a unified framework and empirical comparison. Decision Support Systems, 40, 213-233.

10. Frias-Martineza, E., Magoulas, G., Chena, S., \& Macredie, R. (2005). Modeling human behavior in user-adaptive systems: Recent advances using soft computing techniques. Expert Systems with Applications, 29, 320-329.

11. Griffith, D. A., \& Palmer, J. W. (1999). Leveraging the web for corporate success. Business Horizons, 42(1), 3-10.

12. Hanani, U., Shapira, B., \& Shoval, P. (2001). Information filtering: Overview of issues, research and systems. User Modeling and User-Adapted Interaction, 11(3), 203-259.

13. Hanson, V., \& Crayne, S. (2005). Personalization of Web browsing: Adaptations to meet the needs of older adults. Universal Access in the Information Society, 4, 46-58.

14. Kim, W. (2002). Personalization: Definition, status, and challenges ahead. Journal of Object Technology, 1(1), 29-40. http://www.jot.fm/issues/issue_2002_05/column3.

15. Kobsa, A., Koenemann, J., \& Pohl, W. (2001). Personalised hypermedia presentation techniques for improving online customer relationships. The Knowledge Engineering Review, 16(2), 111-155. 
16. McCrickard, S. D., \& Chewar, C. M. (2003). Attuning notification design to user goals and attention costs. Communications of the ACM Archive, 46(3), 67-72.

17. Murthi, B. P. S., \& Sarkar, S. (2003). The role of the management sciences in research on personalization. Management Science, 49(10), 1344-1362.

18. Nielsen, J. (1993). Usability Engineering. New York: Academic Press.

19. Papanikolaou, K., Grigoriadou, M., Kornilakis, H., \& Magoulas, G. (2003). Personalizing the interaction in a Web-based educational hypermedia system: the case of INSPIRE. User Modeling and User-Adapted Interaction, 13, 213-267.

20. Piller, F. T., \& Stotko, C. (2002). Four approaches to deliver customized products and services with mass production efficiency. In: T. S. Durrani (Ed.), Proceedings of the IEEE international engineering management conference. Managing technology for the new economy (Vol. II, pp. 773-778). Cambridge University, UK, 18-20 August 2002.

21. Preece, J. (2000). Online communities: designing usability, supporting sociability. Chichester: Wiley.

22. Resnick, P., \& Varian, H. R. (1997). Recommender systems. Communications of the ACM, 40(3), 56-58.

23. Riemer, K., \& Totz, C. (2003). The many faces of personalisation: An integrative economic overview of mass customisation and personalisation. In M. M. Tseng \& F. T. Piller (Eds.), The customer centric enterprise: advances in mass customization and personlization (pp. 35-50). New York/Berlin: Springer.

24. Sarner, A., Berg, T., \& Janowski, W. (2001). Personalization: customer value beyond the Web. Gartner Inc. Strategic analysis report, R-14-2601, 10 September 2001, http://www.gartner.com.

25. Schiaffino, S., \& Anandi, A. (2004). User-interface agent interaction: personalization issues. International Journal of Human-Computer Studies, 60, 129-148.

26. Schonberg, E., Cofino, T., Hoch, R., Podlaseck, M., \& Sparagen, S. L. (2000). Measuring success. Communications of the ACM, 43(8), 53-57.

27. Schubert, P., \& Ginsburg, M. (2000). Virtual communities of transaction: the role of personalization in electronic commerce. Electronic Markets, 10(1), 45-55.

28. Schubert, P., \& Leimstoll, U. (2003). Extending ERP systems in SMEs into personalized e-commerce applications. In Proceedings of the tenth research symposium on emerging electronic markets (pp. 207-217). Bremen: University of Bremen.

29. Sicilia, M. (2005). Teaching e-commerce personalization technology: the need for a comprehensive view. Journal of Information Technology Education, 4, 85-96.

30. Spiliopoulou, M. (2000). Web usage mining for Web site evaluation. Communications of the ACM, 43(8), 127-134.

31. Swearingen, K., \& Sinha, R. (2001). Beyond algorithms: An HCI perspective on recommender systems. In Proceedings of the SIGIR 2001 workshop on recommender systems.

32. Telang, R., \& Mukhopadhyay, R. (2005). Drivers of web portal use. Electronic Commerce Research and Applications, 4, 49-65.

33. Teltzrow, M., \& Kobsa, A. (2004). Communication of privacy and personalization in e-business. In: Proceedings of the WHOLES workshop A multiple view of individual privacy in the networked world, Stockholm, Sweden.

34. Viorres, N., Koutsabasis, P., Arnellos, A., Darzentas, J. S., Velasco, C., Mohamad, Y., Spyrou, T., \& Darzentas, J. (2003). An approach for personalisation and content adaptation of Internet applications based on user and device profiles. In Proceedings of HCI international 2003 (HCII 2003), 24-26 June 2003, Heraklion, Crete.

35. Wietsma, R., \& Ricci, F. (2005). Product reviews in mobile decision aid systems. In Proceedings of pervasive mobile interaction devices (PERMID 2005). http://www.medien.ifi.lmu.de/permid2005.

36. Wu, D., Tremaine, M., Instone, K., \& Turoff, M. (2003). A framework for classifying personalization scheme used on e-commerce Websites. In Proceedings of the 36th Hawaii international conference on system sciences (HICSS'03).

37. Xu, D., \& Wang, H. (2006). Intelligent agent supported personalization for virtual learning environments. Decision Support Systems, 42(2), 825-843.

Panayiotis Koutsabasis Dr. Panayiotis Koutsabasis is an adjunct lecturer at the department of Product and Systems Design Engineering, University of the Aegean. He has a PhD from the University of the Aegean (2002), and MSc (1997) and BSc (1995) in Information Systems from the Athens University of Economics and Business. He has been working for more than 10 years in research projects in the areas of humancomputer interaction, collaborative systems, e-commerce, distance learning, design support environments, 
Web design, evaluation and accessibility, software agents and multi-agent systems. He has published in international scientific journals and conferences in the aforementioned areas. His research interests are wide ranging, including: human-computer interaction, design methodology, systems thinking and practice, design for all, collaborative systems design, evaluation and implications, evaluation of interactive systems, personalization and mass customisation, user modelling and profiling, artificial intelligence and decision support systems.

Modestos Stavrakis received a Bachelor of Arts (honours) in Creative Visualisation (1999) and Masters of Science in Computer Aided Graphical Technology Applications (2000) from the University of Teesside. He works as a researcher in the areas of multimedia design, 3D modelling, virtual reality installations design, collaborative systems design for supporting design processes and the development of assistive technologies related to the support of visually impaired. Currently he is a $\mathrm{PhD}$ candidate in the area of Collaborative Systems Design in the Department of Product and Systems Design Engineering at the University of the Aegean. His research has led to the co-authoring of journals and conference publications and book chapters in the areas of $\mathrm{HCI}$, digital arts, computer assistive technologies, virtual reality and distance/e-learning.

Nikos Viorres is a PhD candidate at the department of Products and Systems Design at the University of the Aegean. He has an MSc (2001) in Interactive Multimedia from the Heriot Watt University Edinburgh and a BSc in Applied Computing and Digital Microelectronics from the University of Dundee. At present, he is an instructor and a researcher at the department of Products and Systems Design, with various publications in international scientific journals and conferences, and has participated in many scientific and research projects, in both research and development. His research interests include: Human computer interaction, collaborative systems, computer supported cooperative work, the open source software model-practices and software architecture of collaborative systems.

Jenny S. Darzentas Dr. Jenny Darzentas (BA Hons, London,UK; PhD City University, London, UK) is a researcher and temporary lecturer in the Department of Product and Systems Design Engineering of the University of the Aegean. She has collaborated in various European funded projects to do with intelligent tutoring systems, decision support systems, human computer interaction, electronic brokerage, on line learning and digital library environments, accessible and inclusive digital environments, as well as higher educational curricula in Design for All. She has spoken at many conferences on these subjects. She has written about models of discourse and explanation, digital library systems, metadata and enabling online information provision, and in co authorship, the use of interaction agents in electronic information brokerage, digital publishing, and designing accessible Internet services.

Thomas Spyrou Dr. Thomas Spyrou is an Assistant Professor in the Department of Product and Systems Design Engineering. His main interest is to research and to apply systems theories and approaches to real-world scenarios, especially in the case of Information Systems for Human Activity Systems. He has over 10 years of teaching experience in systems design, theories and methodologies of design, as well as various areas of human-computer interaction. He has been director or executive member of technical committees for the design of large scale network and services infrastructures such as University of the Aegean network, Greek Secondary Educational network, Greek Universities network and Greek Research and Technology Network. He has served as part of the Ministry of the Aegean's Think Tank. He has directed and participated in a number of projects both funded nationally, and by the European Union. He has published in scientific journals and participated in conferences, in the areas of information systems design, holistic systems design, artificial intelligence, decision support systems, intelligent tutoring systems, simulation and security.

John Darzentas Professor John Darzentas (BSc Athens Greece; MSc Sussex UK, PhD London UK) is Chair of Operational Research and Head of the Department of Product and Systems Design Engineering, University of the Aegean. He has held various academic positions in Britain, Finland and Greece, including lectureships at Universities in London and Reading in the UK, visiting professorships at the University of Athens, and the Abo Akademi, in Turku, Finland. He has collaborated in and led many research projects, both in the UK and Greece as well as projects funded by the European Union on a range of subjects, including Systems Thinking; Decision Support; Simulation; Knowledge Management; Learning Technologies, Human Computer Interaction; Design, and lately Design for All and e-Accessibility. He has spoken, and been invited to speak, at many conferences on various aspects of these topics, he is on the editorial board of several journals, and the author of a substantial number of papers in scientific journals and books. He is referee in a number of journals including the Journal of Fuzzy Sets and Systems, Journal of the Operational Research Society, Computers and Operational Research, etc. 